\title{
Uso de Corticoides en COVID-19 y posibles daños de su inadecuada prescripción
}

\section{Use of Corticosteroids in COVID-19 and possible damages of its inadequate prescription}

DOI

\author{
Luis Pampa-Espinoza, ${ }^{1, a}$, Fernanda Montalván-Miranda ${ }^{2, b}$, Martín Yagui-Moscoso ${ }^{1, c}$
}

https://doi.org/10.35434/rcmhnaaa.2021.14Sup1.1179

\section{Señor editor:}

La infección por COVID-19 es un grave problema de salud pública en el Perú. Uno de los medicamentos del cual tenemos evidencia clara de su uso en COVID-19 son los corticoesteroides; son fármacos lipofílicos de acción nuclear. Se indican en enfermedades inflamatorias y autoinmunes en donde el propio sistema inmune ataca las células de nuestro organismo ${ }^{(1)}$.

Los cambios a nivel inmunitario por el uso de corticoides dependen de la dosis y días de tratamiento (mayor inmunosupresión a dosis mayores y más días) son disminución de la función fagocítica (en neutrófilos, monocitos y macrófagos) principalmente por el bloqueo del factor de transcripción NF-kB, alteración de la migración de los neutrófilos a los sitios de inflamación o infección, disminución de la producción de citocinas inflamatorias (IL-1, IL-2, IL-6, IL-8, FNT- $a$ y INF- $\gamma$ ), linfopenia aguda de 4 a 6 horas (Linfocitos $T>$ Linfocitos B), aumento del catabolismo de las inmunoglobulinas (disminución de IgG y IgA en $10-20 \%$ de su valor basal), entre otros cambios que conllevan a una inmunosupresión que puede perdurar hasta semanas tras la suspensión del tratamiento ${ }^{(2)}$. Por todo lo descrito es entendible que su evento adverso más frecuente es el aumento de riesgo a infecciones [RR: 5.30 (3.80 to 7.41) vs sin corticoides] $^{(3)}$.

En la COVID-19, como en cualquier otra patología infecciosa, debe conocerse el tiempo de enfermedad y severidad para tomar decisiones terapéuticas. Tiene 3 fases en pacientes sintomáticos con COVID-19: Etapa I (Leve- infección temprana), etapa II (moderado- afectación pulmonar sin o con hipoxia por mayor inflamación pulmonar), etapa III (severa hiperinflamación sistémica y linfocitopenia que podría conducir a insuficiencia orgánica múltiple que puede provocar la muerte $)^{(4)}$.

En fase temprana de COVID-19 (sin hipoxemia), Xiao Tang et al compararon dos grupos de pacientes (que usaron metilprednisolona y no usaron). La duración de la detectabilidad del ARN viral de garganta en el grupo de metilprednisolona fue de 11 días (rango intercuartílico, 6-16 días), significativamente más larga que en el grupo sin corticoides ( 8 días [2-12 días], $\mathrm{p}=0,030$ ). También la citometría de masas mostro, que las células T CD3 +, células T CD8 + y células NK en el grupo de metilprednisolona que fueron significativamente más bajas que las del grupo de control después de la aleatorización. Esto sugiere que el uso temprano a corto plazo de corticosteroides podría suprimir las células inmunitarias, lo que puede prolongar la diseminación del SARS-COV2 en pacientes con neumonía ${ }^{(5)}$. Esta observación cobra fuerza con el estudio RECOVERY que evalúa mortalidad a los 28 días encontró que no hubo evidencia que la dexametasona proporcionara algún beneficio entre pacientes que no estaban recibiendo asistencia respiratoria (17,8\% vs. $14,0 \%$; RR, 1,$19 ;$ IC del $95 \%, 0,92$ a 1,55$)$ sino por el contrario se describió mayor porcentaje de fallecidos en ese grupo(6), esto también reflejado en el metaanálisis de Laura Pasin et al en donde los corticoides aumentaron la mortalidad en los pacientes que no requirieron oxigeno $(17 \% \mathrm{v} 13 \%, \mathrm{RR}=$ $1,23$ [IC del 95\%: 1,00-1,62], $\mathrm{p}=0,05$ número necesario para dañar $\{\mathrm{NND}\}=29)^{(7)}$.

\author{
FILIACIÓN \\ 1. Unidad de Intervenciones estratégicas \\ CNSP, Instituto Nacional de Salud, Perú. \\ 2. Unidad de Seguridad y Salud en el Trabajo \\ OGA, Instituto Nacional de Salud, Perú. \\ a. Medico Infectologo. \\ b. Medico Ocupacional.
c. Medico Patólogo Clínico. \\ ORCID \\ 1. Luis Pampa-Espinoza \\ 0000-0002-2392-587X \\ 2. Fernanda Montalván-Miranda \\ 0000-0003-3411-3006 \\ 0000-0002-3737-5709 \\ CORRESPONDENCIA \\ Luis Eduardo Pampa Espinoza \\ Dirección: Instituto Nacional de Salud. Cápac \\ Yupanqui 1400 - Jesus María, Lima 11, Perú \\ Teléfono: (511) 7481111 \\ EMAIL \\ lpampa@ins.gob.pe \\ CONFLICTOS DE INTERÉS \\ Los autores niegan conflictos de interés. \\ FINANCIAMIENTO \\ Autofinanciamiento. \\ REVISIÓN DE PARES \\ Recibido: / 20/08/2021 \\ Aceptado:/ 19/09/2021

\section{COMO CITAR} \\ Pampa-Espinoza, L., Montalván-Miranda, F., \& \\ Yagui-Moscoso, M. Uso de Corticoides en COVID- \\ 19 y posibles daños de su inadecuada \\ prescripción. Revista Del Cuerpo Médico \\ Hospital Nacional Almanzor Aguinaga Asenjo, \\ 2021,14 ( S u p 1), 81 - 83 . \\ https://doi.org/10.35434/rcmhnaaa.2021.14S \\ up1.1179
}




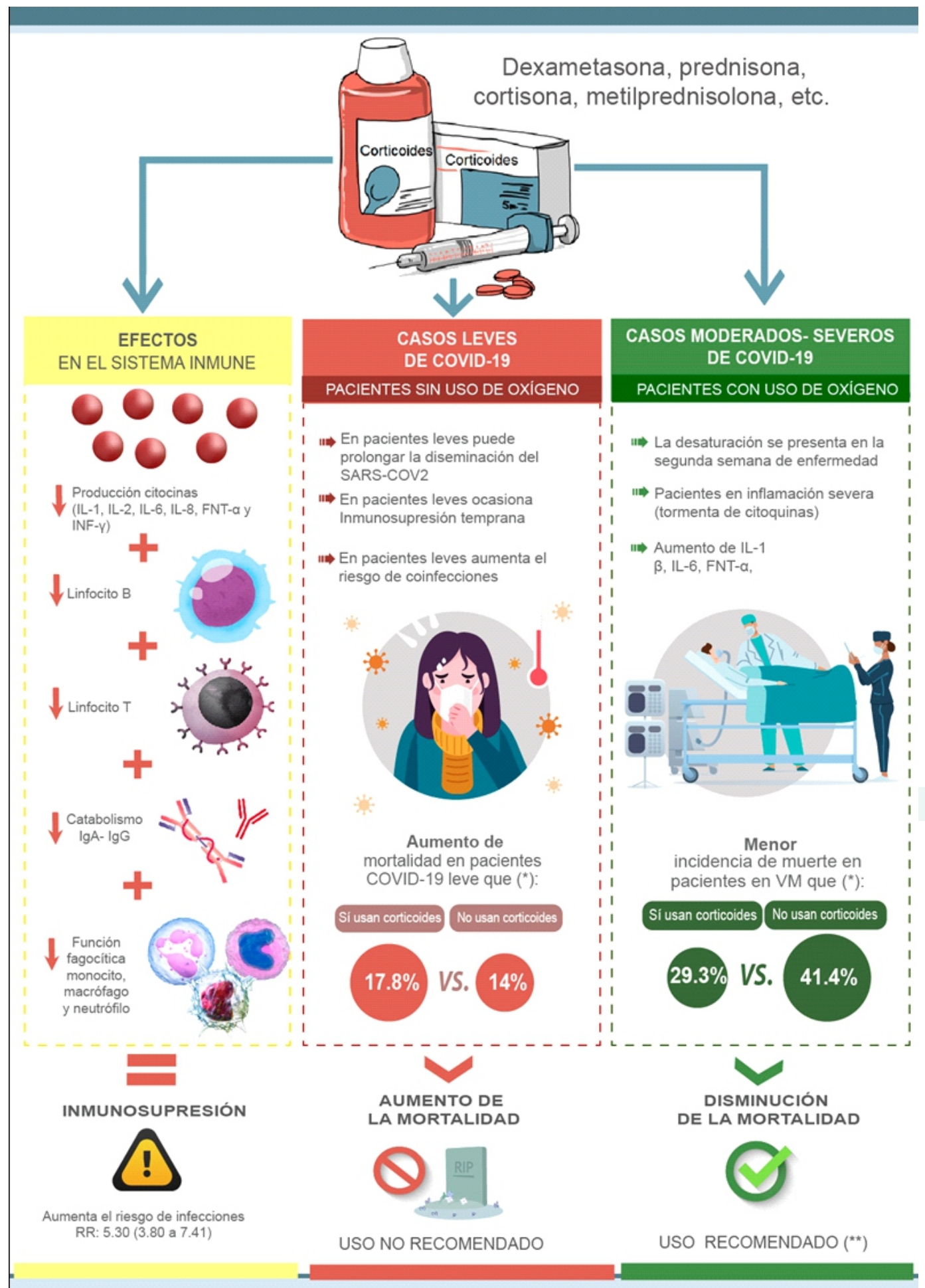

Leyenda: $\left(^{*}\right)$ Estudio RECOVERY, disponible en: https://www.nejm.org/doi/10.1056/NEJMoa2021436, $\left({ }^{* *}\right)$ Directrices de la IDSA sobre el tratamiento y el manejo de pacientes con COVID 19, disponible en: https://www.idsociety.org/practice-guideline/covid-19-guideline-treatment-and-management/.

Figura 1.

Efectos y uso de corticoides en pacientes con COVID-19.

Los corticoides en fase tardía de COVID-19 (con hipoxemia), en esta fase los pacientes presentan una respuesta inflamatoria excesiva conocida como "tormenta de citoquinas" (aumento de IL-1 B, IL-6, FNT- $a$, INF- $\gamma$, etc.); esto ocasiona lesiones pulmonares que causan clínicamente caída de la saturación de oxígeno (desaturación). El reporte final del estudio RECOVERY que evalúa mortalidad a los 28 días encontró que en el grupo de dexametasona, la incidencia de muerte fue menor que en el grupo de atención habitual entre los pacientes que recibieron ventilación mecánica 
invasiva $(29,3 \%$ frente al 41,4\%; razón de tasas, 0,64; IC del $95 \%, 0,51$ a 0,81 ) y entre los que recibieron oxígeno sin ventilación mecánica invasiva $(23,3 \%$ frente a $26,2 \%$; razón de tasas, 0,82; IC del 95\%, 0,4\%) ${ }^{(5)}$.

Se puede recomendar el uso de corticoides en pacientes con soporte de oxígeno en COVID-19 con cuadro moderado o severo. Se desaconseja su uso en pacientes con cuadro leve de COVID-19 sin soporte de oxígeno.

Se advierte en pacientes leves con COVID-19 el uso de corticosteroides podría estar provocando empeoramiento de su cuadro clínico y con aumento de infecciones comunitarias e intrahospitalarias. Es importante que se haga un control de su prescripción por las autoridades pertinentes en salud en el Perú y de ser posible mecanismos de sanción ante la evidencia clara de sus daños en pacientes que no tengan indicación de su uso.

\section{REFERENCIAS BIBLIOGRÁFICAS}

1. Glucocorticoid effects on the immune system - UpToDate [Internet]. [citado 26 de abril de 2021]. Disponible en: https://www.uptodate.com
2. Sternberg EM. Neural regulation of innate immunity: a coordinated nonspecific host response to pathogens. Nat Rev Immunol [Internet]. 2006 [citado 26 de abril de 2021];6(4):318-28. Disponible en: https: / / bit.ly/3CvXnNd

3. Waljee AK, Rogers MAM, Lin P, Singal AG, Stein JD, Marks RM, et al. Short term use of oral corticosteroids and related harms among adults in the United States: population based cohort study. The BMJ [Internet]. 2017 [citado 6 de septiembre de 2021];357:j1415. Disponible en: https: / / bit.ly/39k0710

4. Siddiqi HK, Mehra MR. COVID-19 illness in native and immunosuppressed states: A clinical-therapeutic staging proposal. J Heart Lung Transplant [Internet]. 2020 [citado 26 de abril de 2021];39(5):405-7. Disponible en: https: / / bit.ly/2XJ0Usx

5. Tang X, Feng Y-M, Ni J-X, Zhang J-Y, Liu L-M, Hu K, et al. Early Use of Corticosteroid May Prolong SARS-CoV-2 Shedding in Non-Intensive Care Unit Patients with COVID-19 Pneumonia: A Multicenter, SingleBlind, Randomized Control Trial. Respir Int Rev Thorac Dis. 2021:100(2):116-26. doi: 10.1159 / 000512063.

6. The RECOVERY Collaborative Group . Dexamethasone in Hospitalized Patients with Covid-19. N Engl J Med [Internet]. 2021 [citado 6 de septiembre de 2021];384(8):693-704. Disponible en: https://doi.org/10.1056/NEJMoa2021436

7. Pasin L, Navalesi P, Zangrillo A, Kuzovlev A, Likhvantsev V, Hajjar LA, et al. Corticosteroids for Patients With Coronavirus Disease 2019 (COVID-19) With Different Disease Severity: A Meta-Analysis of Randomized Clinical Trials. J Cardiothorac Vasc Anesth [Internet]. 2021 [citado 6 de septiembre de 2021];35(2):578-84. Disponible en: https://www.ncbi.nlm.nih.gov/pmc/articles/PMC7698829/ 